\title{
WiMAX- Appropriate Technology to Provide Affordable Access to ICTs Infrastructure and Services in Developing Countries
}

\author{
F.A. Ibikunle*, S.N. John \\ *Covenant University, CST/EIE, Ota, Ogun-state, Nigeria. \\ * faibikunle2@yahoo.co.uk
}

Keywords: Broadband, Access, Developing, WiMAX, ICT,

\begin{abstract}
WiMAX is a broadband wireless standard that enjoys widespread support from both the computer and telecommunications industries worldwide, making this technology particularly cost effective. It is engineered to deliver significant business benefits to operators and users in diverse environments (enterprise, consumer, emerging, public service), geographies and demographies (urban, suburban, rural), both over the short and long terms. The paper intends to highlight some points that make WiMAX the most appropriate technology solution to favor the broadband ICTs access in developing countries.
\end{abstract}

\section{Introduction}

The idea that access to information open doors to wider economic and social development opportunities is not new. In 1984, the "Missing Link Report" pointed to the fact that the lack of telecommunication infrastructure in developing countries impedes economic growth, but with a scope limited to access to telephones rather than today's wider concept of Information and Communications Technologies (ICTs) access and usage. In 1996, the ITU initiated a United Nations project for the "Right to Communicate"' aimed at providing access to basic ICTs for all, with motivation to reduce information poverty for developing countries. Thus, during the first WSIS held in Geneva in December 2003, the "Digital Divide"' was defined as the unequal access to ICTs [6]. Although this unequal access usually apply to differences between countries (the international digital divide) e.g. comparing developed and developing countries or regions; within countries (the domestic digital divide); and most importantly the divide between rural and urban, well educated or poorly educated populations or poor and rich citizens. Despite the various parameters and selected criteria (e.g. Internet host and/or users, fixed and mobile telephones) that can be considered or use to expressed an overall trend of growing ICTs disparities between and within countries, the availability and the quality of the access (i.e. the physical telecommunication infrastructure) is the key to a quick and reliable development of ICTs in the countries. Looking closer to the statistics as published by the different official bodies such as ITU or the World Bank in figure 1, it is clear that the gap in ICTs access between developed and developing countries do exist $[2,3]$.
There are many reasons and barriers why, until now, broadband ICT access was mainly deployed in developed countries and more precisely in urban areas (see figure 2). However it can easily be explained that economics and existing technologies are the main drivers (and barriers in developing countries) to ICTs. Economics in the first case because, as any early entrepreneur in this new business, operators and service providers are naturally inclined to first serve the most populated areas (i.e. dense, rich cities and suburbs) where most of the potential customers are located instead of less populated areas such as remote and rural areas. In the same way, while developed countries and urban areas are requiring higher and higher bit rates for multimedia applications, rural areas in developing countries are still at first favoring voice communication with a slow evolution towards ICTs. Moreover, while developed countries already have existing telecommunication infrastructure ready to evolve and the financial resources to invest and pay for new services, developing countries still suffer from the lack of basic infrastructures (not only telecommunication infrastructures, but also power supply, roads), and more crucial, have great difficulty to mobilize the necessary financial resources. This is what we call as the "demand factor". Technologies in the second case because, until now, existing wired or wireless technologies have inherent limitations either in performances or in capacity (e.g. the $6 \mathrm{Km}$ maximum distance from the exchange for ADSL) or the Line Of Site (LOS) Customer Premise Equipment (CPE) location from the base station for wireless access. And even if such limitations can be overcome using other complementary backbones or equipments (optical fibers or microwaves links, remote switching units.etc), the extra cost of these new equipments, of their deployment and their operation directly impacts the business model. This is what we call the "cost factor". So, both the "Demand and Cost" factors are the major barriers to the broadband access as identified by ITU in [3].

The paper is organized as follows: section two defines WiMAX, the Forum and Profiles; Section three describes why and how WiMAX will be a key element in this new important worldwide objective to provide an equitable and affordable access to ICTs infrastructure and services; The various usage scenarios to illustrate the ability of WiMAX to address different applications are shown in section four; and the paper ended with the conclusion. 


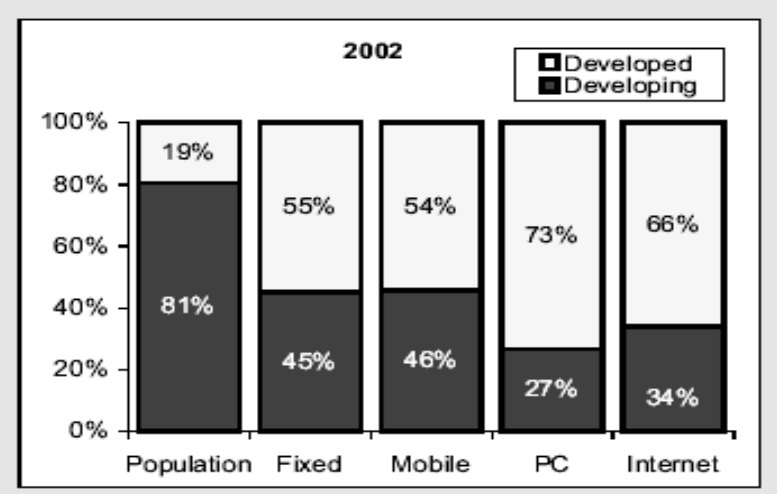

Fig. 1: Gap in ICTs access between developed and developing countries.

Source: ITU World Telecom indicator database

\section{Barriers}

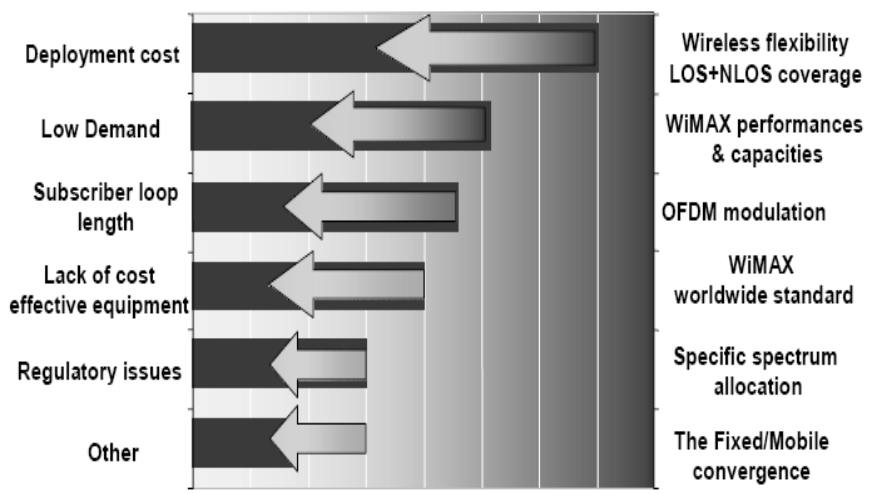

Fig. 2: Major Barriers to ICTs and WiMAX Solutions Source ITU 2003

\section{What is WiMAX?}

WiMAX stands for "World Interoperability for Microwave Access'. It is a broadband wireless technology that supports fixed, nomadic, portable and mobile access. WiMAX is largely supported by the computer and the telecommunications industry, cost-effective and standard base. It is engineered to deliver the latest type of ubiquitous fixed and mobile services such as VoIP, Information Technology and Video at very low cost. WiMAX systems are able to cover a large geographical area, up to $50 \mathrm{~km}$ and to deliver significant bandwidth to endusers up to $72 \mathrm{Mbps}$. To meet the requirements of different types of access, two versions of WiMAX have been defined. The first is based on IEEE 802.16-2004 and is optimized for fixed and nomadic access. The initial WiMAX Forum CERTIFIED products will be based on this version of WiMAX. The second version is designed to support portability and mobility, and will be based on the IEEE 802.16e amendment to the standard. Table 1 shows how WiMAX supports different types of access and their requirements[1].

\section{Why WiMAX as solution?}

Compared with other wired solution such as ADSL, or any other wireless or satellite system, WiMAX based access networks will enable operators and service providers to costeffectively reach million of new potential customers providing them with broadband ICTs access. This is even truer for developing countries and rural areas for which the cost/profitability and the demand factors are essential. This obviously includes adequate coverage, reliability, performances (throughput), capacity and applications.

\begin{tabular}{|c|c|c|c|c|c|}
\hline Definition & Devices & $\begin{array}{l}\text { Locations/ } \\
\text { Speed }\end{array}$ & Handoffs & $802.16-2004$ & $802.16 \mathrm{e}$ \\
\hline Fixed access & $\begin{array}{l}\text { Outdoor and indoor } \\
\text { CPES }\end{array}$ & $\begin{array}{l}\text { Single/ } \\
\text { Stationary }\end{array}$ & No & Yes & Yes \\
\hline Nomadic access & $\begin{array}{l}\text { Indoor CPES, } \\
\text { PCMCIA cards }\end{array}$ & $\begin{array}{l}\text { Multiple/ } \\
\text { Stationary }\end{array}$ & No & Yes & Yes \\
\hline Portability & $\begin{array}{l}\text { Laptop PCMCIA } \\
\text { or mini cards }\end{array}$ & $\begin{array}{l}\text { Multiple/ } \\
\text { Walking } \\
\text { speed }\end{array}$ & $\begin{array}{c}\text { Hard } \\
\text { handoffs }\end{array}$ & № & Yes \\
\hline Simple mobility & $\begin{array}{l}\text { Laptop PCMCIA } \\
\text { or mini cards, } \\
\text { PDAs or smartphones }\end{array}$ & $\begin{array}{l}\text { Multiple/ } \\
\text { Low vehicular } \\
\text { speed }\end{array}$ & $\begin{array}{c}\text { Hard } \\
\text { handoffs }\end{array}$ & № & Yes \\
\hline Full mobility & $\begin{array}{l}\text { Laptop PCMCIA } \\
\text { or mini cards, } \\
\text { PDAs or smartphones }\end{array}$ & $\begin{array}{l}\text { Multiple/ } \\
\text { High vehicular } \\
\text { speed }\end{array}$ & $\begin{array}{c}\text { Soft } \\
\text { handoffs }\end{array}$ & No & Yes \\
\hline
\end{tabular}

Table 1: Types of Access to a WIMAX Network

The WiMAX standard has been developed with many objectives in mind [9]. These are:

Flexible Architecture: WiMAX supports several system architectures, including Point-to-Point, Point-to-Multipoint, and ubiquitous coverage. The WiMAX MAC (Media Access Control) supports Point-to-Multipoint and ubiquitous service by scheduling a time slot for each Subscriber Station (SS). If there is only one SS in the network, the WiMAX Base Station (BS) will communicate with the SS on a Point-to- Point basis. A BS in a Point-to-Point configuration may use a narrower beam antenna to cover longer distances. Wireless is more flexible and thus easier to deploy according to the market demand. Although most of the existing wireless technologies suffer from limited range and coverage (usually a few hundred meters around the base station) resulting in very costly combination of technologies (wired and/or wireless), WiMAX technology benefits in a wide coverage and can be deployed as a Point-to-MultiPoint "last mile" connection but also as part of the backhaul to the PSTN and Internet access points [8]. The WiMAX role in an access network is illustrated in figure 3. With potential range of 30 to 50 kilometers in Line Of Site (LOS) conditions, WiMAX offer a huge improvement over all existing broadband wireless technology.

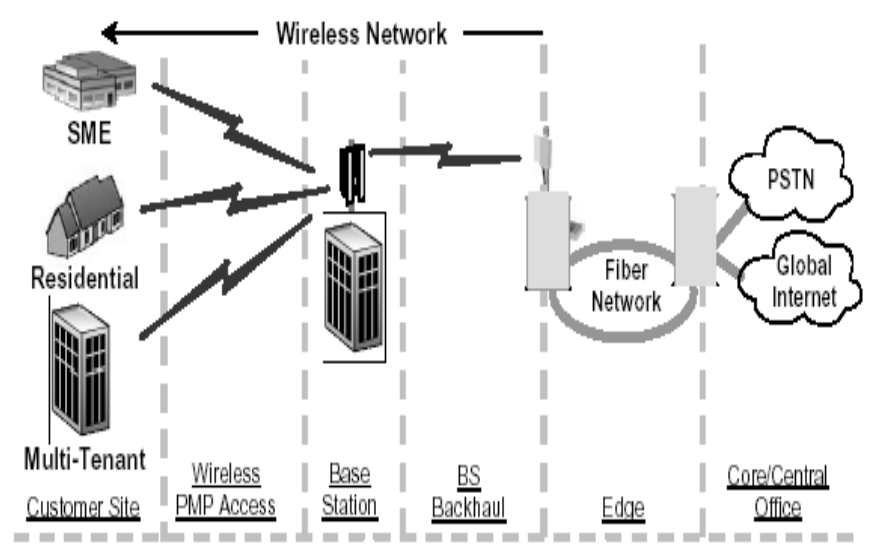

Fig. 3: WiMAX Network Description

Quick Deployment: Compared with the deployment of wired solutions, WiMAX requires little or no external plant construction. Ease of installation is one of the key issues to lower deployment costs in developing countries or rural areas. In rural areas, the consequences of the long distances from the core network access point and the scattered location of villages, farms... in the countryside makes any deployment very costly. In developing countries, the lack of main infrastructure 
(electricity, roads.), and environmental condition (temperature, humidity) adds on the difficulty. Thanks to the NLOS/LOS coverage advantage, the operator/service provider can easily plans a 95\% predictability coverage ensuring high installation success rates and controls deployment costs. A quicker and simpler installation with a much greater rate of success means operators spend less money rolling out their networks. WiMAX NLOS capability also allows indoors self install CPEs within several Km radius.

Worldwide Standardization: Developed and supported by the WiMAX forum (more than 300 members), WiMAX will become the worldwide technology based standard for broadband and will guaranty interoperability (i.e. multivendor CPEs), reliability and evolving technology, but also (thanks to high volumes and integration) will ensure equipments with very low cost. With low CPEs cost as one of the first objective, business model can easily be profitable even in developing countries.

Mobility: The IEEE 802.16e amendment has added key features in support of mobility. Improvements have been made to the OFDM and OFDMA physical layers to support devices and services in a mobile environment. These improvements, which include Scalable OFDMA, MIMO, and support for idle/sleep mode and hand-off, will allow full mobility at speeds up to $160 \mathrm{~km} / \mathrm{hr}$. The WiMAX Forum-supported standard has inherited OFDM's superior NLOS (Non-Line Of Sight) performance and multipath-resistant operation, making it highly suitable for the mobile environment.

Wider Coverage: Even more important than the range limitation, the coverage (i.e. the capability to reach any potential customer within the base station covering area) is essential for the operator/service provider. While many currently available wireless broadband solutions can only provide Line-Of-Site (LOS) coverage, WiMAX, thanks to its OFDM technology, has been optimized to provide excellent Non-Line-Of-Site (NLOS) coverage (up to $15 \mathrm{Km}$ around the base station) and long range transmission up to $50 \mathrm{Km}$ in LOS conditions. Combining both LOS and NLOS coverage, WiMAX is the ideal solution for getting the exact requested coverage in the most economical way.

High Capacity: Using higher modulation (64-QAM) and channel bandwidth (currently $7 \mathrm{MHz}$, with planned evolution towards the full bandwidth specified in the associated IEEE and ETSI standards), WiMAX systems can provide significant bandwidth to end-users.

Spectrum Flexibility: In line with the objective to become the worldwide standard based technology for broadband, WiMAX will use a single radio covering all licensed and unlicensed frequency bands allocated by the ITU for such services. This are:

- The two licensed bands 3.3-3.8 GHz and 2.3-2.7 GHz

- One license exempt band 5.725-5.85 GHz.

In addition to the flexibility offered to address all national spectrum situations, this single radio, will makes base stations and customer premises equipment costs very attractive.

Multi-application Technology: Following the normal trend of digitalization and packet transmission and switching, WiMAX uses the Internet protocol and thus supports all multimedia services from Voice over IP (VoIP) to high speed internet and video transmission. WiMAX allows service providers to offer all the latest generation of services and beyond, thanks to a throughput up to tens of Mbps. With regard to the potential users, this means that WiMAX have the capacity to deliver services from households to SME's, SOHO's, Cybercafés, Multimedia Telecentres, Schools and Hospital. See table 2 for Wimax range of applications [9].

\begin{tabular}{|c|c|c|c|}
\hline Class Description & $\begin{array}{l}\text { Real } \\
\text { Time? }\end{array}$ & Application Type & Bandwidth \\
\hline Interactive Gaming & Yes & Interactive Gaming & $50-85 \mathrm{kbps}$ \\
\hline \multirow{2}{*}{ VolP, Video Conference } & \multirow{2}{*}{ Yes } & VolP & $4-64 \mathrm{kbps}$ \\
\hline & & Video Phone & $32-384 \mathrm{kbps}$ \\
\hline \multirow{3}{*}{ Streaming Media } & \multirow{3}{*}{ Yes } & Music/Speech & $5-128 \mathrm{kbps}$ \\
\hline & & Video Clips & $20-384 \mathrm{kbps}$ \\
\hline & & Movies Streaming & $>2 \mathrm{Mbps}$ \\
\hline \multirow{3}{*}{ Information Technology } & \multirow{3}{*}{ No } & Instant Messaging & $<250$ byte messages \\
\hline & & Web Browsing & $>500 \mathrm{kbps}$ \\
\hline & & Email (with attachments) & $>500 \mathrm{kbps}$ \\
\hline \multirow{2}{*}{$\begin{array}{l}\text { Media Content Download } \\
\text { (Store and Forward) }\end{array}$} & \multirow[t]{2}{*}{ No } & $\begin{array}{l}\text { Bulk Data, Movie } \\
\text { Download }\end{array}$ & $>1 \mathrm{Mbps}$ \\
\hline & & Peer-to-Peer & $>500 \mathrm{kbps}$ \\
\hline
\end{tabular}

Table 2: WiMAX Ranges of Applications

\section{Usage scenarios}

Based on its technical attributes and service classes, WiMAX is suited to supporting a large number of usage scenarios. WiMAX technology will revolutionize the way we communicate. It will provide total freedom to people who are highly mobile, allowing them to stay connected with voice, data and video services. It will allow people to go from their homes to their cars, and then travel to their offices or anywhere in the world, all seamlessly. To illustrate the ability of WiMAX to address the applications outlined above, several representative usage scenarios are outlined below [9].

\subsection{Cellular Backhaul}

Majority of backhaul is done by leasing T1/E1 services from incumbent wire-line operators. With the WiMAX technology cellular operators will have the opportunity to lessen their independence on backhaul facilities leased from their competitors. Outside the US, the use of point-to-point microwave is more prevalent for mobile backhaul, but WiMAX can still play a role in enabling mobile operators to

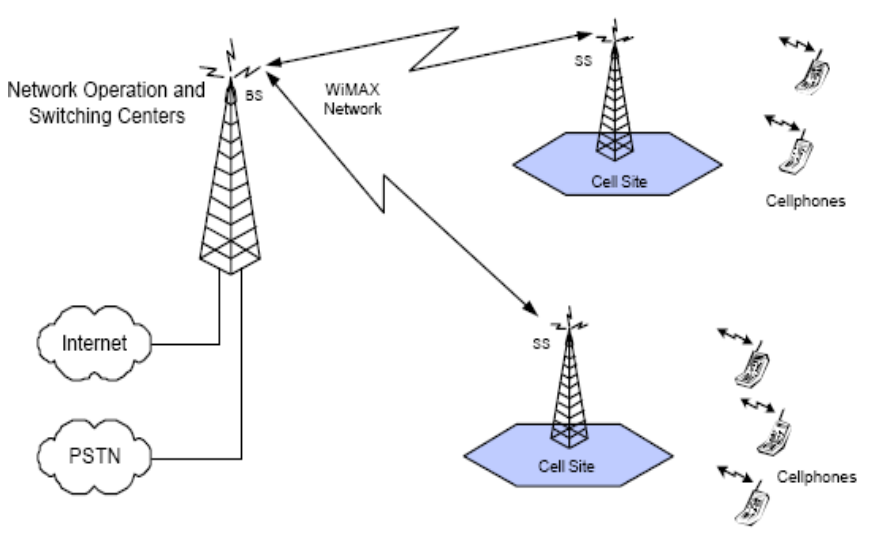

Fig. 4: Cellular backhaul

cost-effectively increase backhaul capacity using WiMAX as an overlay network. This overlay approach will enable mobile operators to add the capacity required to support the wide range of new mobile services they plan to offer without the risk of disrupting existing services. In many cases this application will be best addressed through the use of 802.16 based point-topoint links sharing the PMP infrastructure. 


\subsection{Public Safety Services and Private Networks}

Support for nomadic services and the ability to provide ubiquitous coverage in a metropolitan area provides a tool for law enforcement, fire protection and other public safety organizations enabling them to maintain critical communications under a variety of adverse conditions. Private networks for industrial complexes, universities and other campus type environments also represent a potential business opportunity for WiMAX. See figure 5.

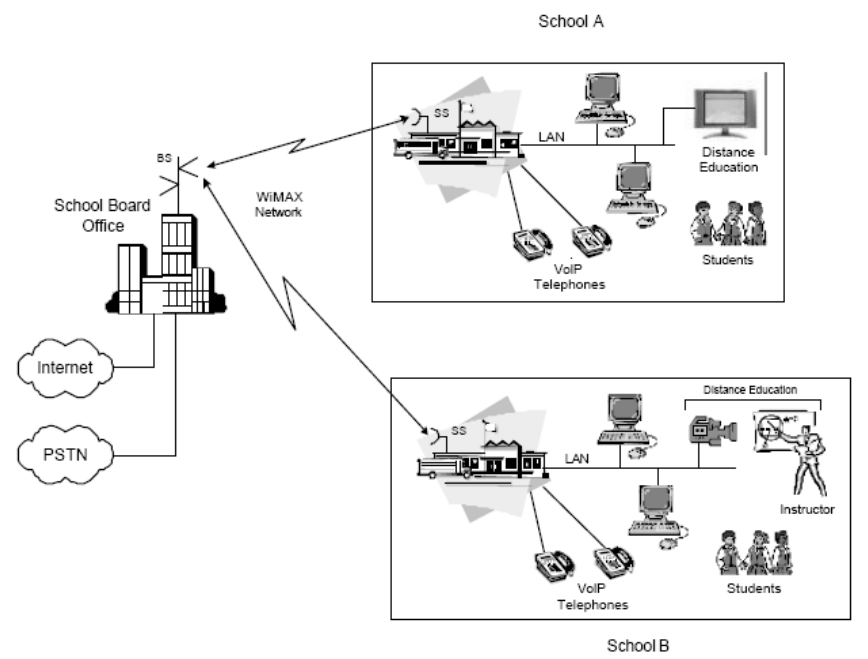

(5a)

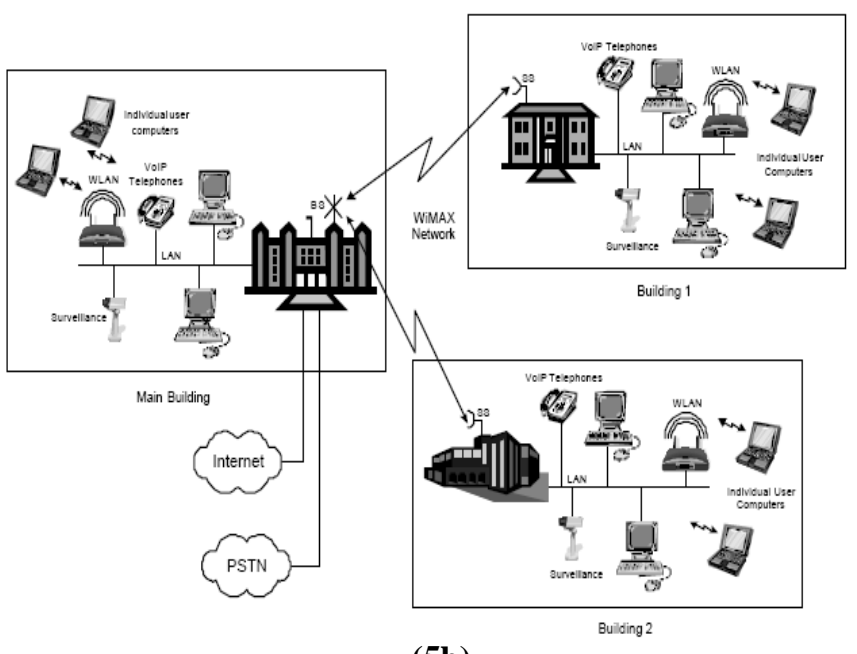

(5b)

Fig. 5: (a) Education network \& (b) Campus connectivity

\subsection{Rural Connectivity}

Service providers use WiMAX networks to deliver service to underserved markets in rural areas and the suburban outskirts of cities, as shown below: The delivery of rural connectivity is critical in many developing countries and underserved areas of developed countries, where little or no infrastructure is available. Rural connectivity delivers much-needed voice telephony and Internet service. Since the WiMAX solution provides extended coverage, it is a much more cost-effective solution than wired technology in areas with lower population densities. It solutions can be deployed quickly, providing communication links to these underserved areas, providing a more secure environment, and helping to improve their local economies.

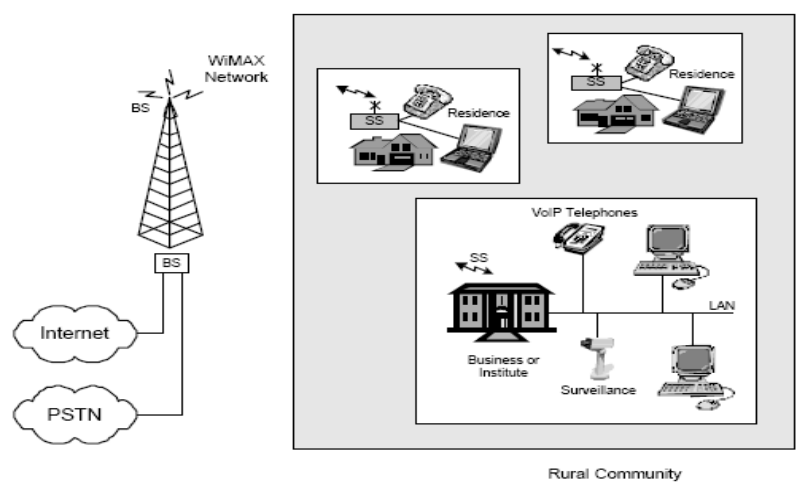

Fig. 6: Rural connectivity

\section{Conclusion}

Demand for wireless broadband access is growing fast and embracing an ever-widening range of applications that encompass fixed, nomadic, portable and mobile data access as well as fixed and mobile voice services, and content streaming. Looking back to the barriers as summarized by ITU in figure 2 and section 3, WiMAX appears clearly as the solution to favor the broadband ICTs access in developing countries. Undoubtedly, WiMAX is a new powerful broadband wireless technology aiming at providing a universal ubiquitous and equitable and affordable access to ICTs infrastructure and services, and thus highly contributing to bridge the "Digital Divide”.

\section{References}

[1] "Air Interface for Fixed Broadband Wireless Access Systems,” IEEE STD 802.16 - 2004, October, 2004.

[2] "Air Interface for Fixed and Mobile Broadband Wireless Access Systems,” IEEE P802.16e/D12, February, 2005.

[3] ITU World Telecomunication Development report 2003.

[4] IEEE 802.16.3c-01/29r4, “Channel Models for Fixed Wireless Applications,” http://www.ieee802.org/16.

[5]Spanning the Digital Divide, bridges.org, Washinton DC.

[6] WSIS Declaration of Principles and Plan of Action, Geneva December 2003.

[7] WiMAX Forum white paper: "WiMAX's technology for LOS and NLOS environments".

[8] WiMAX Forum white paper: "Fixed, nomadic, portable and mobile applications for 802.16-2004 and 802.16e WiMAX networks", November 2005.

[9] WiMAX Forum white paper: "Can WiMAX Address your Applications?” October, 2005. 